This is the author's version of a work that was submitted to / accepted for publication. To cite this chapter:

Hemming, P. J. 2014. Geographies of faith in education. In: Brunn, S. D. ed. Geographies of Faith in Education. Netherlands: Springer, pp. 877-891. (10.1007/978-94-017-9376-6_44)

\title{
Geographies of Faith in Education
}

\section{Peter J. Hemming}

This chapter address the contentious issue of faith in education, especially the role that religion plays in and around state-funded education systems and some of the issues that arise as a consequence. It focuses on the significance of geography for making sense of these debates and its potential to enrich the interdisciplinary field of research in this area. The chapter begins by outlining recent developments in the 'new' geographies of education, particularly the significance of space, place and scale for analysing educational processes. It then goes on to consider three main areas in which religion often features in educational arrangements and experiences. The first of these is the contested curriculum, where religious education, science and sex education are central to the discussion. The second is the faith schools debate, which features competing constructions of community, some that emphasise belonging and cohesion and others that emphasise segregation and division. The third issue is the relationship between religion, citizenship and identity, particularly the extent to which schools recognise and accommodate religious minorities. In each of these contexts, the importance of geography is highlighted through reference to various spatial and scalar dimensions. The chapter ends with reflections on the contributions that geographical scholarship on religion in education could make to broader questions about the purpose of education and the place of religion in wider society.

Key words: education, geography, faith, religion, scale, space

\subsection{Introduction}

Over the last decade, religion has begun to take a more prominent role in the social sciences than was previously the case. Developments related to globalization, such as migration and international mobility have led to more religiously diverse populations in the West, while geopolitical events such as the 9/11 attacks and the subsequent "war on terror" have also highlighted the significance of religion for making sense of the world. Scholars have begun to realize that a purely secular lens is not always sufficient for understanding social processes in their entirety and that the importance of 
religion cannot be underestimated, even in so-called "secular" societies (for example, ESRC/AHRC Religion and Society Programme in the UK, http://www.religionandsociety.org.uk/ ). In the context of geography, for example, Kong (2010) has usefully outlined a number of "global shifts," including urbanization and inequality, deteriorating environment, aging, and increased mobility, where an engagement with religion could help to better understand human responses to these key issues.

The study of education is no exception to this trend and interest in the significance of religion in educational contexts has also continued to grow. While social studies on education have, in the past, often been concerned with issues such as class, economy and culture, and later gender, ethnicity and globalization, it is reasonable to assert that less attention has been paid to religion. This has now started to change and bodies of literature can be found that explore key themes such as religion in the curriculum, faith schools, and religious identity and difference in education. In fact, these are the three areas that make up the main part of this chapter, specifically the contribution that a geographical approach can bring to such issues and debates.

Education has not always been of major concern in geography, although, like religion, the topic is currently rising in prominence in geographical circles. However, there has been very little scholarly interest in the intersection between religion and education from geographers, despite concepts such as space and scale having much to offer debates in this area. In this chapter, I explore some of the relevant issues and literature relating to the three key areas mentioned in the last paragraph in order to highlight the significance of such debates to geography. I begin by introducing the recent body of work on geographies of education and some of the relevant tools and concepts that can help to enhance the study of religion in education. 


\subsection{Geographies of Education}

A good place to start in developing a geographical approach to the study of religion in education is with a consideration of the 'new' geographies of education. This emerging sub-discipline has been outlined by two recent reviews in Progress in Human Geography. The first, by Hanson Theim (2009), highlights the significance of geography for interrogating the political and economic aspects of educational processes, in contrast to Holloway et al. (2010) emphasis on their social and cultural dimensions, particularly the role of young participants and their families. Despite these differences in perspective, both reviews, nevertheless, point to four key areas where geography has started to make inroads into grappling with the significance of education.

The first area relates to "geographies of educational provision and consumption," encompassing the role that education plays in communities of identity and social networks, the structuring of neighborhoods and housing decisions, the transnationalization of higher education markets, and experiences of education in the global majority world. The second area is concerned with both "formal and informal curricula and spaces of learning," including issues of citizenship and national identity, the development of social subjectivities, the nature of curriculum governance and the role of a range of actors in supporting or contesting these processes. The examples given later in this chapter fall mainly within these first two areas.

The third area identified by the two reviews is the issue of "knowledge spaces," particularly the role of higher education in economic and political processes, educational restructuring as a result of globalization, and the resultant experiences of students and their impact on the urban landscape. The final area relates to "institutional restructuring," including economically, politically and socially. This is concerned with the relationship between education and the neoliberal project, whether through its engagement with concepts such as rationalization and privatization, or through 
the shifting responsibilities for social reproduction and the challenges this might present for the project.

Although the two reviews successfully identify a number of thematic areas for which the "new" geographies of education have shown a certain amount of coverage, they only travel so far down the road of developing specific geographical approaches to education. Hansom Thiem (2009) does point to the need for geographies of education to not only pay attention to the role of space in education ("inward-looking" studies), but also the ways that education can affect external macro processes and their spatial manifestations (“outward-looking” studies). Holloway et al. (2010), however, problematize this inward- and outward- categorization. They argue that many studies focusing on children, youth and families that could be classed as "inward" in this sense, actually reveal important links between educational and other wider spaces and discourses.

As a geographer writing from within education studies, Taylor (2009) has also made some interesting contributions to the development of a distinctly geographical approach to the study of educational processes. He utilizes the concept of operational scale to outline a range of research agendas that have the potential to focus on micro, meso and macro scales. These scales include learners, sites of learning, communities of learners, local authorities, central governments, and international contexts. Of course, there have been numerous debates in human geography about how scale should be theorized, and many of these have moved away from hierarchical notions, towards inter-linking and socially constructed understandings. More recent conceptions have questioned the usefulness of scale altogether, instead emphasizing networks and practices (for example, Moore, 2008). But as MacKinnon (2010) has argued, this does not necessarily mean that scale as an analytical category should be discarded. Social actors may well employ hierarchical understandings of scale in order to make sense of the world, and this may result in real material effects. 
The fluidity of scale is something that Taylor (2009) recognizes as a limitation of his model, while nevertheless, identifying a whole range of current research examples that fit within it, such as embodied geographies, school design, residential segregation, education markets, devolution and globalization. The contribution of Holloway et al. (2010) to this way of thinking about scale is to highlight how both formal and informal education micro-spaces may connect and relate to wider scales and spaces of reference. A model of scale that takes analytical scale seriously, but nevertheless recognizes the fluidity and socially constructed nature of the concept, as well as the connections and linkages between spaces and scales, is, therefore, central to the present chapter.

In the remainder of this chapter, I focus on key debates in the field of faith in education, drawing out some of the spatial and scalar implications, including the construction of public and private space, the relationship between local and national power, different understandings of community and community cohesion, and the way in which citizenship operates as a multi-scalar process. I explore the first of these with reference to the place of religion in the curriculum, as it operates as a contested space.

\subsection{The Curriculum as a Contested Space}

One of the key functions of schools and other educational institutions is the transfer of knowledge through various curricula. Although many countries have moved towards standardized national curricula in recent times, their content and form often remain fiercely contested. The place of religion in the curriculum is no exception, although it maintains a very different role depending on the particular national context in question. An examination of this issue reveals some interesting 
relationships, firstly between the role of religion in public and private space, and, secondly, between power at the national and the local level in educational processes.

The extent to which religion should be viewed as a public or a private affair is often an important factor in debates about its role in the curriculum. As a political theory, liberalism generally sees religion as something that should rightly be confined to private space, achieved through the separation of church and state (Locke, 2003, cited in Martin, 2010:61). In reality, though, many liberal democratic states do not always maintain a separation between church and state, and even if they do, religion and state politics are often intensely intertwined, even if they are not presented as such (Berger, 1999). The place of religion is often, therefore, much more complex than its official status implies, as is illustrated in the examples below. Furthermore, as will be apparent, the debate over public and private space often plays out through the dynamic between local and national power.

\subsubsection{Religious Education}

While many state-funded education systems allow little or no official place for religion in the curriculum, others, such as in England and Wales, have a long tradition of including religious education (RE) in the standard provision offered to pupils. The place of religion in the English school curriculum very much reflects the historical role of the Churches in the national education system. The Church of England originally introduced schooling for the masses in the early $19^{\text {th }}$ century, and after universal state education was established in 1870, a "dual system" was gradually developed through the acts of 1902 - 1944. This enabled the incorporation of existing church schools into the wider system, offering a pragmatic solution to a difficult logistical problem. 
"Religious instruction" had always been a key component of the curriculum in church schools, and was also adopted by state schools as a means to uphold national standards of morality (Baumfield, 2003). Yet the subject gradually lost its confessional basis in state schools, particularly following the 1960s and 1970s and the religious diversification that occurred as a result of new migration from the former colonies. Increasingly, the subject was instead taught from an educational perspective through a phenomenological focus on the various elements of the world religions. The subject was eventually renamed "religious education," remaining a compulsory part of the curriculum in the 1988 Education Reform Act.

It is at this point that one of the key geographical issues emerged, highlighting RE as a contested space. By the late 1980s, the subject had become an area of considerable controversy, particularly over the balance between different religions taught. This tended to reflect concerns regarding the emphasis given to Christianity, viewed by many as part of the national cultural and religious heritage, compared with other religions, and the recognition and respect their inclusion extended to religious minorities. At the time, central government succeeded in sidestepping this debate in the 1988 Education Reform Act by omitting RE from the national curriculum, but nevertheless ensuring that it remained a compulsory part of the whole curriculum.

This was achieved by devolving the power to set the RE programs of study to the local level - specifically to Standing Advisory Committees for Religious Education (SACREs). SACREs are groups of advisors, teachers and representatives from the major faiths in each particular local area. Although there is a requirement for all local syllabuses to show a certain amount of priority to Christianity, there is still substantial freedom for SACREs to develop RE content that reflects their locality. Crucially, it also allows central government to avoid becoming involved in controversial discussions over what should be taught in each local area. Localism, or devolving power to the local 
level, was, therefore, used strategically to sidestep difficult debates about the role of religion and RE in the public sphere.

In the last decade or so, various developments have placed the subject of RE under renewed scrutiny in England, both in terms of its place in the curriculum and its actual content. It is of interest that all of these developments occurred at the national level, potentially changing the balance of power between the state and the local areas. Firstly, the introduction of compulsory citizenship education in all secondary schools in England from 2002 onwards represented a potential competitor with RE for timetable space in an already crowded curriculum. This led to suspicions on the part of many RE teachers that the new subject could herald the demise of their own area of expertise, partly because of the substantial overlap between the two subjects on issues such as common values and respect for difference (for example, see Watson, 2004).

Secondly, the publishing in 2004 of a non-statutory national framework for RE by the then QCA government curriculum organization (Qualifications and Curriculum Authority, 2004), marked a shift away from the more locally-based SACRE system established by the 1988 Education Reform Act. Although the framework was presented as advisory only, inevitably it influenced many SACREs in devising their local syllabuses. The national framework was also significant in that it was the first time that secular philosophies and less well-known religions were suggested as important areas to cover in RE lessons, alongside Christianity and the other major world faiths. If teaching about religion in publically-funded schools was considered controversial by some, the inclusion of explicitly non-religious philosophies, such as atheism and humanism, in the RE curriculum further fuelled debates about the place of religion in the public sphere, and its relationship to secular functions and systems of thought. 


\subsubsection{Science and Sex Education}

Religion and its relevance to the school curriculum is, however, much wider than the issue of RE. There have been many high profile cases in the U.S. of educational organizations and institutions attempting to introduce the teaching of creationism or "intelligent design" into science lessons, presented as a valid alternative to theories of evolution. School boards and state legislators have, in the past, come into conflict with the U.S.Supreme Court, which in 1987, outlawed religious content in science lessons on the grounds that this would be advancing a particular religion. Despite this ruling, states such as Louisiana and Tennessee have, in the last few years, been successful in passing state laws that permit the discussion of alternative theories alongside evolution in the school classroom (for example, see Flock, 2012, http://www.washingtonpost.com/national/law-allowscreationism-to-be-taught-in-tenn-public-schools/2012/04/11/gIQAAjqxAT story.html). These examples can be viewed in the wider context of the U.S. "culture wars," whereby education has become a key battleground between conservative and progressive forces.

Central to many of these debates, is the (conservative) argument that secular schools are not promoting totally neutral philosophies, but are teaching from an explicitly liberal position. Teachers could, therefore, be accused of subverting the religious beliefs of children and discriminating against particular religious positions (Collins, 2006). In these situations, the rights of parents to raise their children in the religious values of their choice grate against the liberal ideal of religion being confined to the private sphere. Pike (2008) has also adopted a similar argument in his analysis of English citizenship education, arguing that it effectively teaches children to "believe" in liberal democracy, when these are values that particular religious communities may not share. Although this is a rather controversial argument, it is nevertheless aligned with the kind of debates that typically occur around such issues. 
Alongside science, the subject of sex and relationship education is another area of the curriculum where religious considerations can be pertinent. Collins (2006) examines a Canadian case study, involving the Board of Surrey School District in British Columbia refusing to allow the use of three particular books in schools that portrayed same sex parents. This incident, and the six years of controversy that surrounded it, highlighted some of the ambiguity around the boundary between public and private space and the relation of religion to this divide. Whereas conservative parental groups maintained that religious values and interests should play a role in public decisionmaking, liberal lobbyists contended that values of dignity and respect of all persons, including sexual orientation, should be paramount, placing religion firmly in the private sphere. After various rulings at different levels of the Canadian legal system, the principle was established that religious beliefs and values could be considered in decisions regarding public education, but not at the expense of issues of equality and social justice. In other words, the place of religion was deemed to be more than merely confined to the private sphere, but not quite as much some conservative lobbyists would have liked.

In both the examples of science and sex education above, power dynamics between local group interests, school boards, state legislators and various levels of law courts were central to the eventual resolution of the issues. Typically in these cases, local control and devolved decisionmaking are favored by conservative interests, in contrast to liberal and progressive concerns for a degree of state oversight to safeguard rights and combat discrimination (Collins, 2006). In many ways, these examples mirror the case of English RE, and the power dynamics between the local and the national scale discussed earlier in the section. As Merrett (1999:599) argues, in these kinds of debates, "the politics of scale are used by the contending sides to determine the appropriate scale for social reproduction." Not only this, but the effective boundary between public and private space, and the place of religion in relation to this divide, is also constituted through these scalar politics between national and local interests. 


\subsection{The Faith Schools Debate}

In addition to the curriculum, religion has often been intertwined with education through the provision of single faith institutions, including schools, colleges or universities. As mentioned in the previous section, universal education in England and Wales was predated by the establishment of a vibrant church school sector, from the start of the $19^{\text {th }}$ century, before being incorporated into the state system. State funding for faith schools is a tradition that has continued in England and Wales, and has been replicated in many other countries, for example, the Netherlands. Yet despite this, the issue remains highly controversial, with arguments for and against such schools regularly rehearsed by politicians, lobby groups and the media (for example, see Jackson, 2003).

Arguments in favor of state-funded faith schools include the following:

- religious needs are better catered for in faith schools;

- faith schools provide choice for parents and diversity of provision;

- faith schools represent justice and fairness for members of different religious groups;

- faith schools foster positive ethos and supportive religious values.

In contrast, arguments against state-funded faith schools include the following:

- faith schools limit pupil autonomy and promote indoctrination;

- faith schools use selection procedures that effectively disadvantage other schools by selecting the best pupils;

- faith schools work against educational aims and equal opportunities;

- the state should not fund religion as it should be a private matter. 
Despite these wide-ranging arguments, the most vigorous debates occur over the issues of community, belonging and social division. It is to these issues that I now turn.

\subsubsection{Faith Schools and Institutional Belonging}

The idea of community is often very central to how faith schools view themselves, and this is illustrated well in the study by Valins (2003) on Jewish schools in England. Valins (2003) outlines how Jewish community leaders and school gatekeepers sought to form and institutionalize desirable religious identities among pupils through educational provision. This was achieved by the construction and maintenance of socio-spatial boundaries between the school community and the outside world. Particularly in Jewish Orthodox schools, faith-based education was viewed as a way to combat the perceived assimilation of Jews into mainstream British (secular) culture. The process of boundary construction and formation was not, however, straightforward but was a contested process, involving different school stakeholders.

Despite the emphasis on religious belonging from community and school leaders, parents of pupils who attended the school often had rather different priorities for what they hoped their children would obtain from their educational experiences. Rather than specific teaching about the Jewish religion, parents instead valued academic standards and a more general sense of Jewish ethos and identity. Even so, some parents continued to hold concerns about isolationism and the need for children to be prepared for dealing with the "outside world." Many parents spoke particularly highly of schools in Liverpool, Birmingham and Glasgow, which due to lower demand for places, also took children from non-Jewish families and were therefore seen as the "best of both worlds." 
Close-knit educational communities of faith are often consistent with state discourses such as parental choice in countries like England, but this may not always be the case, and there may be some misalignment between the aims and objectives of the school on the one hand, and the state on the other. Kong (2005) examines how Islamic schools in Singapore negotiate their community identities within the multi-cultural context of a state with a secular and modernist vision. In Singapore, religious schools are considered a right for groups, but whereas state schools are constructed as modern and multicultural, Islamic schools are seen as the opposite. For the Muslim community, however, such schools are seen as important alternative "educators" for reproducing religion and a holistic education. In order to negotiate this tension, Islamic schools have also attempted to show that they are modern and forward looking by making links with other schools and investing in new facilities. As was the case in Valins's (2003) study, the construction of a school community of belonging is shown to be a contested process, one that often involves the involvement of social and political actors from various different scales of reference.

\subsubsection{Faith Schools and Community Cohesion}

The issue of faith schools and isolationism has also been central to recent debates about social and community cohesion. Of course, the idea of community cannot only refer to the state of belonging to a particular religious or social group, but can also be concerned with the wider geographicallybased community or neighborhood (for example, see Clark, 2009 for review of the community concept). This type of community has received much attention in recent years, particularly in innercity urban contexts, amongst concern about community fragmentation and division (e.g. see Putnam, 2000). In England, the 2001 riots in northern towns and cities such as Bradford, Oldham and Burnley were of particular significance, when some of the reports into these events highlighted the segregated nature of the education system in these urban centers (for example,. Ouseley, 2001). In the case of faith schools, the question is whether such institutions work to promote or erode 
social cohesion between different faith, ethnic and cultural groups. While one argument suggests that children must experience interfaith and intercultural encounters in order to understand each other, another insists that values of tolerance and acceptance can instead be taught as part of the curriculum.

As Dwyer \& Parutis's (2012, in press) recent work highlights, often the argument hinges on the particular understanding of community and community cohesion that is employed. The paper explores political and policy discussions in England regarding the place of state-funded faith schools in the education system and their relationship to debates about social integration and division. The authors focus on two specific mechanisms introduced by the state in order to respond to criticism of the state-funded faith school sector. These included a universal requirement for all schools to "promote community cohesion" (and to be assessed on this by the school inspectorate), as well as the introduction of a new "admissions code" for faith-based schools. Here, the focus is on the first of these mechanisms, particularly how various epistemological constructions of community were central to understanding the dynamics of the debate.

In the case of the requirement for schools to "promote community cohesion," Dwyer \& Parutis (2012, in press) show how responses to this new regulation from faith schools were often based on a re-working of the community cohesion concept. This re-working emphasized the theologically based values of respect and tolerance taught to pupils as part of the faith ethos, rather than actual inter-faith contact or encounter as envisaged by the state. Although there were some examples of "linking events," whereby schools with culturally homogenous intakes would develop partnerships with other more demographically diverse schools, these were generally in the minority. The desire from the government in 2006 to introduce a requirement for all new faith schools to reserve 25 percent of places for families of different or not faith, also met with resistance from parts of the faith school sector, and the attempt was eventually abandoned (Dwyer \& Parutis, 2012, in 
press). The understanding of "community" and "community cohesion" adopted by many (although by no means all) faith schools, therefore focused much more on the school religious community than the local neighborhood based community (see also Hemming, 2010), or alternatively drew on notions of a "global community" through the teaching of universally applicable values.

Ironically, the idea of the community as a geographically based neighborhood has, in some instances, started to take on much greater significance in the context of faith-based schooling. This is particularly the case regarding the admissions process, often accused of inadvertently allowing the selection of the most affluent or academically able pupils rather than operating purely by religious criteria (for example, see Allen \& West, 2011). The effect of this, so it is argued, is to further exacerbate social divisions of various kinds in the local neighborhood. Recent research by Butler \& Hamnett (2012, in press) found that, in the crowded educational market of East London, where good state schools are in rather short supply and private school fees are often unaffordable, parents increasingly see faith schools as an attractive option for schooling their children. In this situation, many parents were willing to go to great lengths to establish their religious credentials in order to meet challenging admissions rules or even relocate to take advantage of the "distance from school" or catchment criteria increasingly used alongside religious considerations to select pupils for oversubscribed faith schools.

Butler \& Hamnett (2012, in press) argue that while parents often emphasize school standards, quality, behavior, ethos and values at such schools, implicit to their enthusiasm for the faith school sector also comes from a desire to find the 'right' social and ethnic mix for their children's social and educational development. Often this involved pupils experiencing limited contact with the ethnic or religious 'other', but not too much contact (see also Byrne, 2006). By subtly insinuating that faith schools are a better reflection of the neighborhood, compared with local state schools that might admit a larger proportion of ethnic minority or working class pupils, these 
parents are effectively constructing their own socially acceptable version of the "local community.". They are also enacting a certain type of community cohesion that ensures contact and encounters with other families that share broadly similar values.

\subsection{Religion, Citizenship and Identity}

The final section of this chapter consists of a focus on the relationship between education, citizenship and religious identity. Although citizenship has traditionally been defined at the scale of the nation, recent work in geography has highlighted its multi-scalar nature, particularly the role of everyday practices in constituting citizenship (Dickenson et al., 2008). Gordon et al.,. (2000) have pointed to the central role that schools play in creating future citizens, particularly in reference to gender, including through formal, informal, physical and embodied space. But religion has, to date, received rather less attention in this context, compared with other social identities such as class, gender and ethnicity. Notable exceptions outside of geography include the work of Nesbitt (2004) and Smith (2005), among others, but there is much potential for geographers to add to these bodies of work.

In my own work, I have been interested in developing and exploring the concept of “religious citizenship.” Building on Joppke’s (2007) three dimensions of citizenship (status, rights and identity), I have defined religious citizenship as "the role of religion in devising criteria for access to state or community membership, the political rights and responsibilities attributed to particular religious groups within that membership, and the religious aspects of collective social/cultural identity that influence belonging" (Hemming, 2011:444). I have also emphasized the significance of everyday practices and discourses to the evolving nature of the dimensions outlined above. 
Although the concept of religious citizenship is relevant and applicable at a variety of scales, in the case of my own research, I have made use of it in the context of education spaces. The idea that religion as an identity is important in its own right creates an alternative lens through which to view work on multiculturalism and education, whereby religion has often been subsumed under the umbrella of "culture" and "ethnicity." As my work has highlighted (Hemming, 2011), religion actually constitutes a further layer of stratification in schools, influencing which pupils are privileged and which are not. In the case of the primary (elementary) case-study school in my research (Rainbow Hill), these positions were often formed through everyday school practices, including the way in which various religions were recognized and accommodated, and the responses of various social actors to these arrangements. Religious citizenship, therefore, influenced the dynamics of belonging that pupils in school experienced and (re)negotiated.

One of the key ways in which schools can extend recognition to religious minorities is to make a commitment to marking or celebrating festivals, either as a formal part of the RE curriculum, or during more informal parts of the school day, such as whole school or class assemblies. Nesbitt (2004) highlights how multi-faith schools in England increasingly celebrate a range of non-Christian festivals, such as Diwali and Eid, alongside the more traditional Christianbased festivities at Christmas and Easter. In my research, Rainbow Hill also marked many of these non-Christian festivals, but often at a much smaller scale than the Christian ones. This created a situation where Christianity, if only in a cultural sense, maintained its primacy as the 'default' religion in school, effectively privileging certain pupils over others, either culturally or religiously.

In the case of religious accommodation and minority rights, the issues of food, dress and prayer needs were significant. As has been observed in previous studies, school lunchtimes can create a context for the reinforcement of difference and the negotiation of children's religious identities (Nesbitt, 2004; Smith, 2005). At Rainbow Hill, the school dinner service catered for 
children in school who only ate Halal meat or were vegetarians due to their religion. The school was also generally quite tolerant of dress needs, such as religious bangles and headscarves, and provided space in the school library for Muslims to pray during Ramadan. Yet this provision for religious minorities only went so far, with curriculum requirements and health and safety legislation taking priority in the case of arrangements for fasting and the wearing of religious jewelry during physical education. Some parents and pupils also complained about the lack of prayer space and problems they encountered with bringing prayer mats into school.

All of these examples highlight the limitations of recognizing and accommodating religious minorities through legal and cultural arrangements developed within a western Christian social context. But what was also interesting, was some of the responses to these arrangements from various social actors connected to Rainbow Hill, often reinforcing, contesting or renegotiating them. On the part of parents, while a few of the participants with minority faiths felt that more could be made of their religious festivals in school, many of the other parents were in favor of the status quo, pointing to England's status as a "Christian country." Similarly, whilst some parents felt that the school could go further in accommodating religious needs such as respecting Sabbath days, others expressed the view that the tolerance and respect extended to religious minorities was not always reciprocated in the case of Christian cultural and religious customs. Such examples highlight the role of particular constructions of the nation and national identity in constituting religious citizenship.

The most fascinating finding from this research study was the response of some of the pupils to the arrangements for recognizing and accommodating religious minorities at Rainbow Hill. These were often quite creative, and included creating provision for prayer space where the institution had failed to do so. One way of achieving this was to construct mental prayer space by changing the words of the Christian prayers so that they were more appropriate for another religion, 
or praying to a different God in the child's head. Another was to use toilet cubicles as private spaces in order to satisfy daily prayer requirements. This last example clearly raises some important issues about the extent to which the school really was providing for pupils' religious needs, when children were forced to disregard the usual customs on cleanliness and purity in order that they could pray. All of these cases point to the way in which children were able to contest and renegotiate religious citizenship through everyday embodied practices.

In its entirety, the study further highlights the multi-scalar nature of citizenship processes and in this case religious citizenship. Although citizenship is a concept that is often discussed in relation to the state, it can be just as useful for making sense of the educational institution as a geographical space and the social processes that take place within and through it. Furthermore, the way in which religious citizenship was reinforced, contested and negotiated, brings to light the significance of a number of other scales, including the nation and national identity and embodied practices within informal spaces. This latter example in particular underlines the continued importance of hierarchical scale when considering issues of power, since it was only at this level that children were able to contest constructions of religious citizenship influenced by the state and the institution. However, this nevertheless implied a rather fluid and interconnected understanding of scale, as Holloway et al. (2010) maintain.

\subsection{Conclusion}

As the study of religion becomes increasingly important in geography and the social sciences in general, the role of faith in education is an area that holds much potential for further scholarly inquiry. The "new" geographies of education sub-discipline offers an initial framework for the development of a distinctly geographical approach to the topic, alongside contributions from the field of educational studies itself, through core concepts such as space and scale. In this chapter, I 
have focused on three areas of interest, including religion in the curriculum, the faith schools debate, and religious identity, difference and citizenship in education and explored some of the ways that geography can shed further light on these issues. Key themes that emerged from this analysis included the construction of public and private space, the relationship between local and national power, different understandings of community and community cohesion, and citizenship as a multi-scalar process.

The coverage of this chapter is, however, necessarily limited, both by the space available, but also by the scarcity of geographical research on religion and education. As a topic that spans a whole range of sub-disciplines in human geography, including social, cultural, urban and political geography, the potential for the development of this field is really quite substantial. Future research needs to engage with some of the major questions in the study of religion, such as secularization, post-secularization, atheism, radicalism and new spiritualities, in order to exam the ways in which these processes are impacting geographically on education. Similarly, many of the contemporary developments in education, such as neo-liberalism, decentralization and privatization may have consequences for both religious institutions and individual believers. Geography has a real contribution to make to these debates and it is important that it does so.

\section{References}

Allen, R. \& West, A. (2010). Why do faith secondary schools have advantaged intakes? The relative importance of neighborhood characteristics, social background and religious identification amongst parents. British Educational Research Journal, 37 (4), 691-712. 
Baumfield, V. (2003). The dignity of difference: Faith and schooling in a liberal democracy (editorial). British Journal of Religious Education, 25 (2), 86-88.

Berger, P.L. (1999). The desecularization of the world: A global overview. In P.L. Berger (Ed.), The desecularization of the world: resurgent religion and world politics (pp. 1-18). Grand Rapids, MI: William B. Eerdmans.

Butler, T. \& Hamnett, C. (2012, in press). Praying for success? Faith schools and school choice in East London. Geoforum.

Byrne, B. (2006) In search of a 'good mix:' 'Race,' class, gender and practices of mothering. Sociology, 40 (6), 1001-1017.

Clark, A. (2009). From neighbourhood to network: A review of the significance of neighbourhood in studies of social relations. Geography Compass, 3 (4), 1559-1578.

Collins, D. (2006). Culture, religion and curriculum: Lessons from the 'three books' controversy in Surrey, BC. The Canadian Geographer, 50 (3), 342-357.

Dickenson, J., Andrucki, M.J., Rawlins, E., Hale, D. \& Cook, V. (2008). Introduction: Geographies of everyday citizenship. ACME: An International E-journal for Critical Geographies, 7 (2), 100112.

Dwyer, C. \& Parutis, V. (2012, in press). 'Faith in the system?' State funded faith schools in England and the contested parameters of community. Transactions of the Institute of British Geographers. 
Flock, E. (2012). Law allows creationism to be taught in Tennessee public schools. Retrieved: May 25, 2012, from http://www.washingtonpost.com/national/law-allows-creationism-to-be-taught-intenn-public-schools/2012/04/11/gIQAAjqxAT_story.html

Gordon, T., Holland, J. \& Lahelma, E. (2000). Making spaces: Citizenship and difference in schools. Basingstoke: MacMillan.

Hanson Theim, C. (2009). Thinking through education: The geographies of contemporary educational restructuring. Progress in Human Geography, 33 (2), 154-173.

Hemming, P.J. (2010). Building a sense of community: Children, bodies and social cohesion. In L. Holt (Ed.), Geographies of Children, Youth and Families: An International Perspective (pp.55-66). London: Routledge.

Hemming, P.J. (2011). Educating for religious citizenship: Multiculturalism and national identity in an English multi-faith primary school. Transactions of the Institute of British Geographers, 36 (3), $441-454$.

Holloway, S.L., Hubbard, P.J., Jöns, H. \& Pimlott-Wilson, H. (2010). Geographies of education and the importance of children, youth and families. Progress in Human Geography, 34 (5), 583-600.

Jackson, R. (2003). Should the state fund faith-based schools? A review of the arguments. British Journal of Religious Education, 25 (2), 89-102. 
Joppke, C. (2007). Transformation of citizenship: Status, rights, identity. Citizenship Studies, 11 (1), 37-48.

Kong, L. (2005). Religious schools: For spirit, (f)or nation. Environment and Planning D: Society and Space, 23 (4), 615-631.

Kong, L. (2010). Global shifts, theoretical shifts: Changing geographies of religion. Progress in Human Geography, 34 (6), 755-776.

Mackinnon, D. (2010). Reconstructing scale: Towards a new scalar politics. Progress in Human Geography, 35 (1), 21-36.

Martin, C. (2010). Masking hegemony: A genealogy of liberalism, religion and the private sphere. London: Equinox.

Merrett, C.D. (1999). Culture wars and national education standards: Scale and the struggle over social reproduction. The Professional Geographer, 51 (4), 598-609.

Moore, A. (2008). Rethinking scale as a geographical category: From analysis to practice. Progress in Human Geography, 32 (2), 203-225.

Nesbitt, E. (2004). Intercultural education: Ethnographic and religious approaches. Brighton: Sussex Academic Press.

Ouseley, H. (2001). Community pride not prejudice. Bradford: Bradford Vision. 
Pike, M.A. (2008). Faith in citizenship? On teaching children to believe in liberal democracy.

British Journal of Religious Education, 30 (2), 113-122.

Putnam, R.D. (2000). Bowling alone: The collapse and revival of American community. London:

Simon \& Schuster.

Qualifications \& Curriculum Authority (2004). Religious education:Tthe non-statutory national framework. London: QCA.

Religion \& Society Programme Website. Accessed: May 25, 2012, from

http://www.religionandsociety.org.uk/

Smith, G. (2005). Children's perspectives on believing and belonging. London: National Children's Bureau for the Joseph Rowntree Foundation.

Taylor, C. (2009). Towards a geography of education. Oxford Review of Education, 35 (3): 651669.

Valins, O. (2003). Defending identities or segregating communities? Faith-based schooling and the UK Jewish community. Geoforum, 34 (2), 235-247.

Watson, J. (2004). Educating for citizenship: The emerging relationship between religious education and citizenship education. British Journal of Religious Education, 26 (3), 259-271. 